\title{
Replication and Resolution of Cloned Poxvirus Telomeres In Vivo Generates Linear Minichromosomes with Intact Viral Hairpin Termini
}

\author{
A. M. DeLANGE, $\dagger$ M. REDDY, $\ddagger$ D. SCRABA, C. UPTON, AND G. McFADDEN* \\ Department of Biochemistry, University of Alberta, Edmonton, Alberta, Canada T6G $2 \mathrm{H} 7$
}

Received 13 February 1986/Accepted 24 April 1986

\begin{abstract}
The covalently closed terminal hairpins of the linear duplex-DNA genomes of the orthopoxvirus vaccinia and the leporipoxvirus Shope fibroma virus (SFV) have been cloned as imperfect palindromes within circular plasmids in yeast cells and recombination-deficient Escherichia coli. The viral telomeres inserted within these recombinant plasmids are equivalent to the inverted-repeat structures detected as telomeric replicative intermediates during poxvirus replication in vivo. Although the telomeres of vaccinia and SFV show little sequence homology, the termini from both viral genomes exist as AT-rich terminal hairpins with extrahelical bases and alternate "flip-flop" configurations. Using an in vivo replication assay in which circular plasmid DNA was transfected into poxvirus-infected cells, we demonstrated the efficient replication and resolution of the cloned imperfect palindromes to bona fide hairpin termini. The resulting linear minichromosomes, which were readily purified from transfected cells, were shown by restriction enzyme mapping and by electron microscopy to have intact covalently closed hairpin termini at both ends. In addition, staggered unidirectional deletion derivatives of both the cloned vaccinia and SFV telomeric palindromes localized an approximately 200-basepair DNA region in which the sequence organization was highly conserved and which was necessary for the resolution event. These data suggest a conserved mechanism of the resolution of poxvirus telomeres.
\end{abstract}

Several families of eucaryotic viruses possess linear double-stranded DNA genomes and have telomeric structures that are well defined. For example, the genomes of poxviruses and parvoviruses contain covalently closed hairpin termini, and replication of their DNA has been shown to proceed via a replicative intermediate in which the hairpin telomeres exist transiently in the inverted-repeat configuration (for reviews, see references 3, 25, and 30). The appeal of poxvirus DNA as a model system to analyze the replication of DNA with hairpin termini is that poxviruses replicate autonomously in the cytoplasm of infected cells and probably encode many, if not all, of the proteins required for viral DNA replication $(12,29,42)$.

The genome of the prototype poxvirus, vaccinia, consists of a single linear 185-kilobase (kb) double-stranded DNA molecule with terminal inverted repeats more than $10 \mathrm{~kb}$ in length. The terminal 104 nucleotides of the viral hairpins are present in two orientations ("flip" and "flop") and include a number of apparently extrahelical bases (1). DNA replication of the hairpin termini results in a dimeric inverted "head-to-head" repeat with the original hairpin at the axis of symmetry. Such an inverted-repeat terminal-sequence arrangement has in fact been observed during the DNA replication of several poxviruses $(13 a, 30,31)$. Using a modification of the telomere cloning system developed by Szostak and Blackburn (37), we have recently cloned the hairpin termini of vaccinia virus in a yeast plasmid vector (14). Unlike the cloned telomeres of yeast cells and the rDNA of Tetrahymena species, however, the resulting recombinant plasmids were circular and had inserts that were

\footnotetext{
* Corresponding author.

$\dagger$ Present address: Department of Human Genetics, University of Manitoba, Winnipeg, Manitoba, Canada.

$\ddagger$ Present address: Department of Microbiology, State University of New York at Stony Brook, Stony Brook, NY 11794.
}

indistinguishable from the replicative intermediate conformation observed during poxvirus replication. Thus, the replicated viral telomeric sequences had not been recognized by the yeast cellular factors involved in the resolution of host telomeres.

To evaluate the utility of these cloned viral telomeres as substrates for enzymes required for poxviral telomere replication and resolution, we have recently developed an in vivo assay that allows replication of exogenous plasmids in poxvirus-infected cells (13a). It was found that plasmid DNA transfected into poxvirus-infected cells was capable of extensive replication, irrespective of the presence of specific viral-DNA replication origin sequences. In this report we have used this in vivo transfection system to examine the events of replication and resolution of the cloned telomere from the orthopoxvirus vaccinia and of a similarily cloned telomere from the tumorigenic leporipoxvirus Shope fibroma virus (SFV). Deletion analysis of the cloned palindromic telomeres of these two poxviruses indicates that within the minimal region required for efficient telomere resolution lies a core conserved target sequence.

\section{MATERIALS AND METHODS}

Enzymes, reactions, and media. Restriction enzymes were purchased from Boehringer Mannheim Biochemicals, Bethesda Research Laboratories, Pharmacia, Inc., and Amersham Corp. T4 DNA ligase, exonucleases III and VII, and T4 DNA polymerase were from Bethesda Research Laboratories, calf intestinal alkaline phosphatase was from Boehringer Mannheim, and DNase I was from Sigma Chemical Co. The T7 gene 3 endonuclease I and Escherichia coli DNA polymerase I were generously donated by P. Sadowski and A. R. Morgan, respectively. Except where indicated, all reactions were performed as suggested by the supplier. The conditions for T7 gene 3 endonuclease I were as follows. Plasmid DNA (10 ng) in $50 \mathrm{mM}$ Tris hydrochloride ( $\mathrm{pH} \mathrm{8)-10}$ 


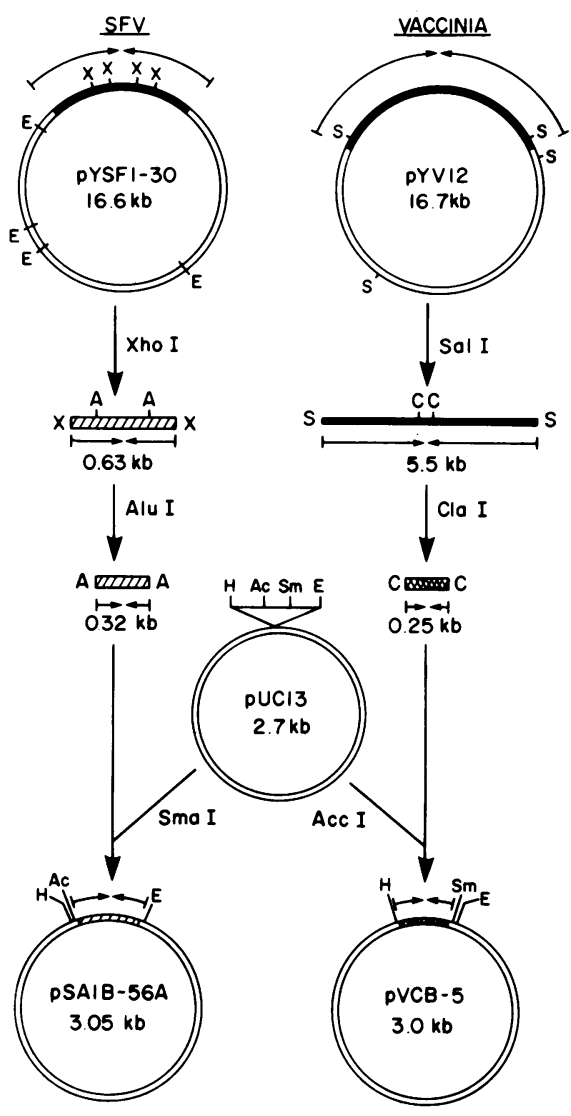

FIG. 1. Cloning protocols for the telomeres of SFV and vaccinia virus. Plasmid pYV12 contains the replicated inverted-repeat configuration of the vaccinia (strain IHD-W) terminal $B c$ I fragment in the yeast- $E$. coli shuttle vector YEp13 (14). pYSF1-30 was similarily derived by ligating the $1.9-\mathrm{kb} \mathrm{Bcll}$ terminal restriction fragment of SFV (strain Patuxent) to the BamHI-linearized yeast-E. coli shuttle vector pJDB219. The pYSF1-30 plasmid replicates as a circular monomer in yeast cells and carries the SFV telomere as an unresolved inverted repeat. Restriction fragments of pYV12 and pVSF130 (not drawn to scale) containing the axis of palindromic symmetry of the viral inserts were then subcloned into $\mathrm{pUC} 13$ and propogated in $E$. coli DB1256 ( $r e c A r e c B$ recC $s b c B$ ). Not shown is pSAB-28A, which contains the palindromic $0.6-\mathrm{kb} A c c \mathrm{I}$ fragment from pYSF130 in the AccI site of pUC13. X, XhoI; E, EcoRI; A, AluI; H, HindIII; Ac, AccI; Sm, SmaI; S, SalI; C, ClaI.

$\mathrm{mM} \mathrm{MgSO}{ }_{4}-1 \mathrm{mM}$ dithiothreitol (DTT)-0.2 $\mathrm{M} \mathrm{NaCl}-50 \mu \mathrm{g}$ of bovine serum albumin per ml was treated with $0.5 \mu \mathrm{l}$ of $\mathrm{T} 7$ gene 3 endonuclease I (diluted 1:10 in 50\% glycerol- $-0.2 \mathrm{mM}$ EDTA-0.5 mM DTT) for $15 \mathrm{~min}$ at $37^{\circ} \mathrm{C}$. DNA used in hybridization experiments was labeled with $\left[\alpha-{ }^{32} \mathrm{P}\right] \mathrm{dATP}$ by nick translation (34). To generate unidirectional deletions in plasmids pSAIB-56A and pVCB-5, plasmid DNA was digested with PstI plus BamHI and $S s t$ I plus $B a m H I$, respectively, to create $3^{\prime}$ overhang sequences on the vector side and 5 ' overhang sequences adjacent to one axis of the palindromic insert (see Fig. 10). Exonuclease III digestions, which proceed unidirectionally into the insert (19), were carried out at $30^{\circ} \mathrm{C}$ in $20-\mu$ l reactions under the following conditions: $66 \mathrm{mM}$ Tris hydrochloride ( $\mathrm{pH} 8), 77 \mathrm{mM} \mathrm{NaCl}$, $5 \mathrm{mM} \mathrm{MgCl}_{2}, 10 \mathrm{mM}$ DTT, 1 to $5 \mu \mathrm{g}$ of plasmid DNA, and 1 to $5 \mathrm{U}$ of exonuclease III. At various times of incubation, samples were removed, supplemented to $10 \mathrm{mM}$ EDTA, and reacted with 1 to $5 \mathrm{U}$ of exonuclease VII for $15 \mathrm{~min}$ at $37^{\circ} \mathrm{C}$.
The digested DNA was extracted with phenol-chloroform, dialyzed, blunted with $\mathrm{T} 4$ polymerase, and ligated at a low concentration ( 1 to $2 \mu \mathrm{g} / \mathrm{ml}$ ).

Media for growth and conditions for transformation of yeast cells were the same as in DeLange et al. (14). The cell lines SIRC (rabbit) and BGMK (monkey), both obtained from the American Type Culture Collection, were cultured as monolayers in Dulbecco modified Eagle's medium plus $5 \%$ fetal calf serum.

Strains and plasmids. Conditions of infection and purification of vaccinia strain IHD-W, SFV strains Patuxent and Kasza, and myxoma strain Lausanne have been described previously $(11,40)$. The $E$. coli-yeast shuttle vector pJDB219 (2) was propagated in E. coli JA221 (recAl leuB6 trp $\Delta E 5$ $h s d R h s d M^{+}$lac Y600). All recombinant plasmids derived from pUC13 (27) were maintained in $E$. coli DB1256 (recA recB2l recC22 sbcB15 hsdR $F^{-}$proA2 his4 thi-l argE3 lac Yl galK2 ara-14 $x y l-5$ mtl-1 str-31 tsx-33). This strain was constructed in F. Stahl's laboratory and obtained through A. Wyman. Bacterial and yeast plasmids generated in this study are illustrated in Fig. 1 and 10. The yeast plasmid pYV12 was described in DeLange et al. (14), and the construction of pYSF1-30 followed a similar protocol, except that pJDB219 was used as the plasmid vehicle. pYSF1-30 is maintained in yeast cells at about 200 copies per cell. The subcloning of the palindromic fragments from the larger yeast plasmids was performed as described in the legend to Fig. 1, with pUC13 vector that had been linearized with either SmaI or AccI and dephosphorylated with calf intestinal phosphatase.

Preparation of DNA. Viral DNA was isolated from purified virions as described elsewhere (24). Plasmid DNA was isolated from yeast cells (17) and $E$. coli (4) by scaled-up alkali extraction procedures. Yeast DNA was further purified by passage through a NACS-52 column as described by the supplier (Bethesda Research Laboratories). To create nicked plasmid DNA exclusively in the linear conformation, plasmid DNA was incubated for $1 \mathrm{~min}$ at $37^{\circ} \mathrm{C}$ with $1 \mu \mathrm{g}$ of DNase I per $\mathrm{ml}$ in $50 \mathrm{mM}$ Tris hydrochloride ( $\mathrm{pH} 7.6)-5 \mathrm{mM}$ $\mathrm{MgCl}_{2}-1 \mathrm{mM}$ DTT $-10 \mu \mathrm{g}$ of gelatin per $\mathrm{ml}$. The reaction was stopped by adding EDTA to $10 \mathrm{mM}$, and the products were resolved by electrophoresis at room temperature in $0.7 \%$ low-melting-point agarose containing $1 \mu \mathrm{g}$ of ethidium bromide per $\mathrm{ml}$. The separated nicked and covalently closed circles were purified by extraction at $65^{\circ} \mathrm{C}$ as described previously (21). The isolation of total DNA from infected and transfected SIRC cells is described by DeLange and McFadden (13a).

Transfection of virus-infected cells and hybridization conditions. The procedure of transfection of plasmids in virusinfected SIRC cells is described elsewhere (13a). Except where indicated, $50 \mathrm{ng}$ of $\mathrm{CaPO}_{4}$-precipitated plasmid DNA was added to previously infected monolayers of $2 \times 10^{6}$ to 3 $\times 10^{6}$ SIRC cells. After extraction, the DNA was digested as indicated in the text, electrophoresed in agarose gels, transferred to nitrocellulose paper by the Southern blotting procedure, hybridized with nick-translated ${ }^{32} \mathrm{P}$-labeled probes, and exposed to X-ray film with intensifier screens (15).

DNA sequencing. The viral inserts of pSAlB-56A and pVCB-5 were sequenced by standard Maxam-Gilbert (23) protocols. The sequences of the individual deletions derived from pSAlB-56A and pVCB-5 were determined by a modification of the dideoxy-chain termination method (35). Plasmids were prepared into templates by the alkaline method recommended by the supplier of the oligonucleotide primers (New England BioLabs, Inc.), and the Klenow reactions were carried out at an elevated temperature $\left(40^{\circ} \mathrm{C}\right)$. The 
electrophoresis of polyacrylamide sequencing gels was usually performed under conditions of high current (60 to $75 \mathrm{~W}$ ) to provide sufficient heat to minimize the secondary structures of the palindromic inserts.

Electron microscopy. Circular and linear duplex DNAs were prepared for electron microscopy by the formamidespreading procedure of Davis et al. (13). To denature the purified minichromosomes derived from pSAB-28A, increasing concentrations of dimethyl sulfoxide were employed. Completely denatured molecules were obtained by heating the DNA at $60^{\circ} \mathrm{C}$ for $30 \mathrm{~min}$ in $75 \%$ dimethyl sulfoxide, diluting to a final formamide concentration of $50 \%$, and spreading on a $20 \%$ formamide hypophase at $37^{\circ} \mathrm{C}$. To visualize the short cruciform structures in pSAlB-56A, the molecules were mounted directly on hydrophilic carbon films from suspensions containing $10 \mathrm{mM}$ magnesium acetate and no cytochrome $c(18)$. These molecules were positively stained with aqueous uranyl acetate and rotary shadowed with $95 \%$ platinum-5\% carbon.

Micrographs were obtained in a Philips EM420 electron microscope operated at $100 \mathrm{kV}$. For the pSAlB-56A molecules, photographs were made with the Philips STEM system in the BF/DF mode, the high resolution photomonitor, and Kodak Pan-X 35-mm film.

Molecules were measured on photographic prints with a Hewlett-Packard Digitizer coupled to a Tektronix Graphics computer. pBR322 DNA $(4,362$ base pairs [bp]) was used as a size standard.

\section{RESULTS}

Propagation of the telomeres of vaccinià virus and SFV in yeast cells and in recombination-deficient $\boldsymbol{E}$. coli. Previously it was shown that the terminal $B c l$ restriction fragment of vaccinia IHD-W could be propagated in yeast cells as an inverted-repeat insert within an autonomously replicating circular plasmid (14). We have repeated this protocol with the 1.9-kb $B c l$ I terminal restriction fragment of SFV, except that a yeast vector with a higher copy number (pJDB219) was used. The plasmids pYV12 and pYSF1-30 (Fig. 1) contained the terminal sequences of vaccinia and SFV, respectively, as inverted repeats with the axis of symmetry at the original hairpin. When pYSF1-30 DNA was isolated and examined by electron microscopy, cruciform structures were readily identified (Fig. 2a), indicating that no major sequence rearrangements of the viral telomeric sequences had occurred during propagation in yeast cells. Since the copy number of these yeast plasmids is too low to permit extensive physical studies of the viral telomeric sequences, several smaller restriction fragments which span the axis of symmetry of plasmids pYV12 and pYSF1-30 were subcloned into pUC13, with $E$. coli carrying $r e c A, \operatorname{rec} B, \operatorname{rec} C$, and $s b c B$ mutations as host. Similar recombination-deficient hosts have also been used successfully to propagate the hairpin sequences of parvovirus termini (10). Figure 1 illustrates the procedure used to generate plasmid $\mathrm{pVCB}-5$, which contains a 242-bp vaccinia insert, and pSAIB-56A, which contains a 322-bp SFV insert. The palindromic nature of the inserted DNA in each case was demonstrated by visualization of extruded cruciforms in extracted plasmid DNA samples (Fig. 2b) and direct DNA sequencing of the DNA inserts (Fig. 3). The observation that the telomeric DNA sequence for the vaccinia strain IHD-W (Fig. 3B) was identical to the DNA sequence previously reported for the telomere of vaccinia strain WR $(1,41)$ indicates that the viral sequences were not rearranged by the cloning procedures and validates
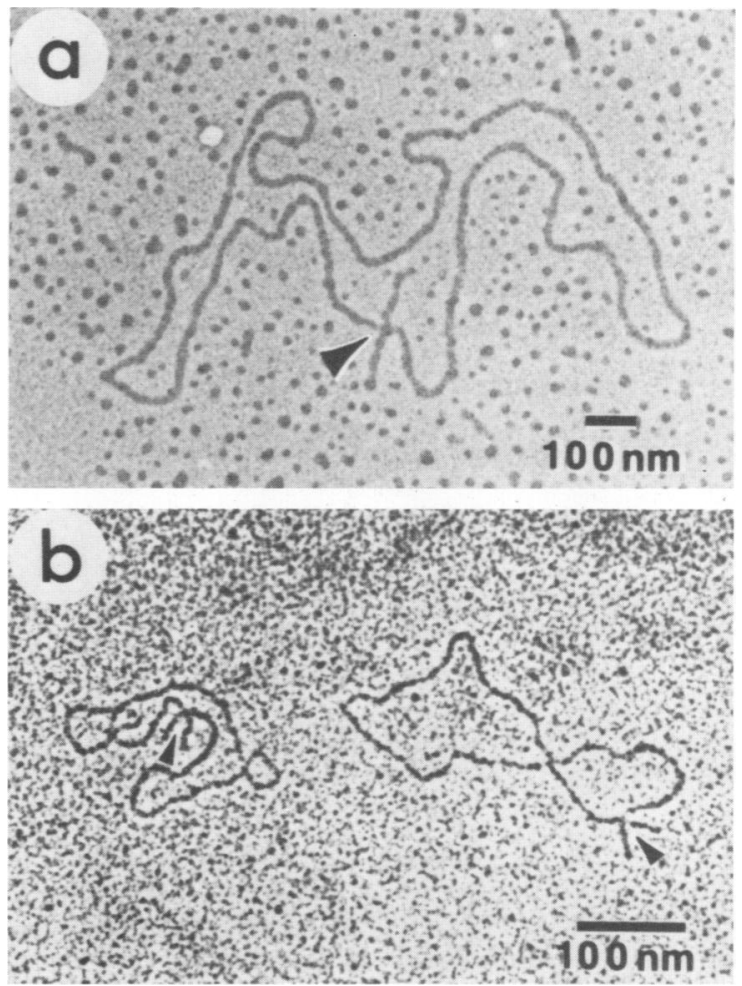

FIG. 2. Electron microscopy of plasmids pYSF1-30 and pSAlB56A. The arrows indicate the location of cruciforms in the purified DNA of (a) the 16.6-kb yeast plasmid pYSF1-30 and (b) the 3.05-kb $E$. coli plasmid pSAlB-56A. To facilitate visualization of cruciforms in plasmid pSAlB-56A, DNA was spread in the absence of cytochrome $c$ (see the text).

the utility of yeast cells as an experimental tool in the analysis of poxvirus telomeres. The DNA sequence of the viral insert in pSAlB-56A also indicates that the viral hairpin structure of SFV, like that of vaccinia, possesses extrahelical bases in two (flip and flop) conformations.

In vivo resolution of the cloned poxviral telomeres. To test whether these cloned telomere sequences can be recognized by trans-acting viral enzymes and resolved to hairpin termini, we utilized the recent observation that calcium phosphate-precipitated plasmid DNA, when introduced into poxvirus-infected cells, is capable of autonomous cytoplasmic replication. This replication of exogenous transfected DNA was found not to require a viral origin sequence and, as a consequence, generates high-molecular-weight head-to-tail concatemers of all circular input plasmids tested (13a). In initial studies, the fate of transfected telomeric sequences was evaluated by transfecting the yeast plasmid pYSF1-30 into rabbit (SIRC) cells infected with SFV or the related leporipoxvirus myxoma. Previous work had indicated that cells infected with either of these leporipoxviruses support a much higher level of replication of transfected plasmid DNA than do cells infected with vaccinia virus (13a). When pYSF1-30 DNA was transfected into control mock-infected cells, virtually all the input DNA had been degraded by $24 \mathrm{~h}$ posttransfection (Fig. 4). On the other hand, when pYSF1-30 was transfected into SFV-infected cells and the DNA was harvested at $3 \mathrm{~h}$ (before viral DNA synthesis had begun) and at $24 \mathrm{~h}$ (after most viral DNA synthesis had finished), substantial replication of the pYSF1-30 plasmid DNA was 
A

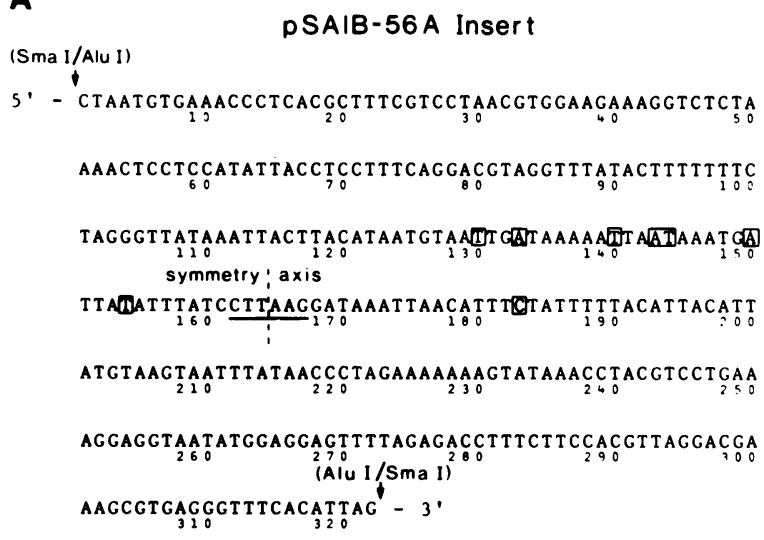

Flip-Flop Hairpins

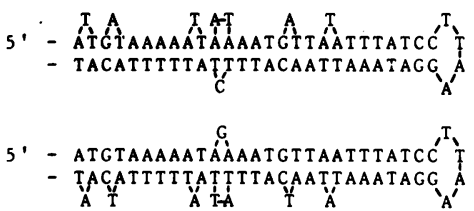

B

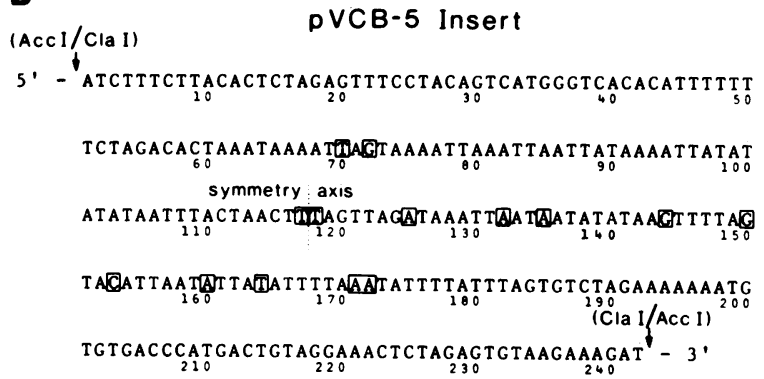

Flip-Flop Hairpins

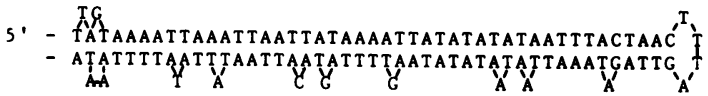

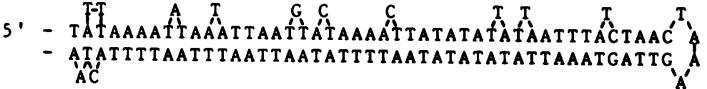

FIG. 3. DNA sequences of the SFV and vaccinia telomeres. The SFV insert of pSAIB-56A (A) and the vaccinia insert of pVCB-5 (B) are displayed in the inverted-repeat configuration and in the resolved flip-flop hairpin configurations. The nonpalindromic bases in the former configuration are indicated in boxes and are drawn as extrahelical in the latter configuration. The AflI site at the symmetry axis of pSAlB-56A is underlined.

observed. The (undigested) DNA harvested at $24 \mathrm{~h}$ contained, in addition to the expected high-molecular-weight concatemers, several major lower-molecular-weight DNA species of between 10 and $25 \mathrm{~kb}$ (Fig. 4). When digested with EcoRI, the input 9.2-kb EcoRI fragment containing the viral insert observed at $3 \mathrm{~h}$ was found by $24 \mathrm{~h}$ to be replaced in large part by two predominant fragments, 6.7 and $2.5 \mathrm{~kb}$ in size, and three minor species of $13.4,9.2$, and $5.0 \mathrm{~kb}$. Only the 6.7- and 2.5-kb DNA fragments of the plasmid and the 9.5-kb terminal fragment of the virus were found intact after the DNA was denatured and quickly chilled before electrophoresis. The generation of these "snapback" 6.7- and $2.5-\mathrm{kb}$ DNA fragments from the progenitor $9.2-\mathrm{kb}$ species is to be expected if a resolution event had taken place at the axis of symmetry of the viral telomeric insert (Fig. 4B). The 13.4- and 5.0-kb fragments shown in Fig. 4 were gel purified and shown to be inverted repeats capable of snapback renaturation to fragments of 6.7 and $2.5 \mathrm{~kb}$, respectively (not shown), and thus were the result of homologous recombination between the viral palindromic sequences aligned in opposite orientations (Fig. 4B). In addition to the plasmidborn telomeric DNA, the authentic viral telomere hairpin $(9.5-\mathrm{kb})$ and dimer replicative intermediate (19-kb) EcoRI fragments were detected by the viral probe in SFV-infected cells. To monitor exclusively the fate of the cloned telomeric sequences, pYSF1-30 was transfected into cells infected with myxoma, a related leporipoxvirus whose genome does not cross-hybridize with that of SFV under conditions of high stringency (9). The results (Fig. 4) indicate that replication and resolution of the SFV sequences occur with high efficiency in myxoma-infected cells, providing firm evidence that myxoma virus can also resolve the telomere of SFV.

Because of superhelical torsion, much of the purified plasmid DNA used in in vivo transfection experiments described in the previous section is present in the cruciform state (Fig. 2a). It is therefore conceivable that the observed resolution events might have occurred not by the viral enzymes normally involved in telomere replication, but by fortuitous nicking of both polynucleotide strands at the Holliday crossover point at the base of the cruciforms of input plasmids. Enzymes that are capable of resolving Holliday structures by this mechanism have been reported for bacteriophages $\mathrm{T} 4, \mathrm{~T} 7$, and $\lambda$ and have also been isolated from yeast cells $(16,20,22,28,39)$. To rule out this possibility, we have introduced single nicks into input plasmid DNA by limited DNase digestion and have purified the nicked form of the plasmid by preparative electrophoresis in the presence of ethidium bromide. The absence of cruciforms in these nicked plasmids was confirmed with (i) T7 gene 3 endonuclease (resolvase), which cleaves across the base of cruciforms (16), but does not react with the line form; and (ii) restriction endonuclease $A f I \mathrm{II}$, which cleaves the cloned telomere of SFV at the $A f I I I$ site at the axis of symmetry (Fig. 3A). Unlike the covalently closed species, the nicked pSAlB-56A plasmid (Fig. 1 and 3) was shown to be quantitatively converted to a $3.05-\mathrm{kb}$ linear species by AflII but was not affected by $\mathrm{T} 7$ resolvase (Fig. 5). With $P v u I I$ (Fig. 5) and BglI (not shown), this sensitive $A$ f $f$ II site on the nicked form of pSAlB-56A and the T7 resolvase site on the covalently closed form of the plasmid were mapped to the axis of symmetry of the viral insert. The lineform and cruciform configurations of both the vaccinia and SFV plasmids were tested individually in subsequent transfections.

To ascertain the fate of the cloned viral telomeres in the lineform and the cruciform configurations, both conforma- 

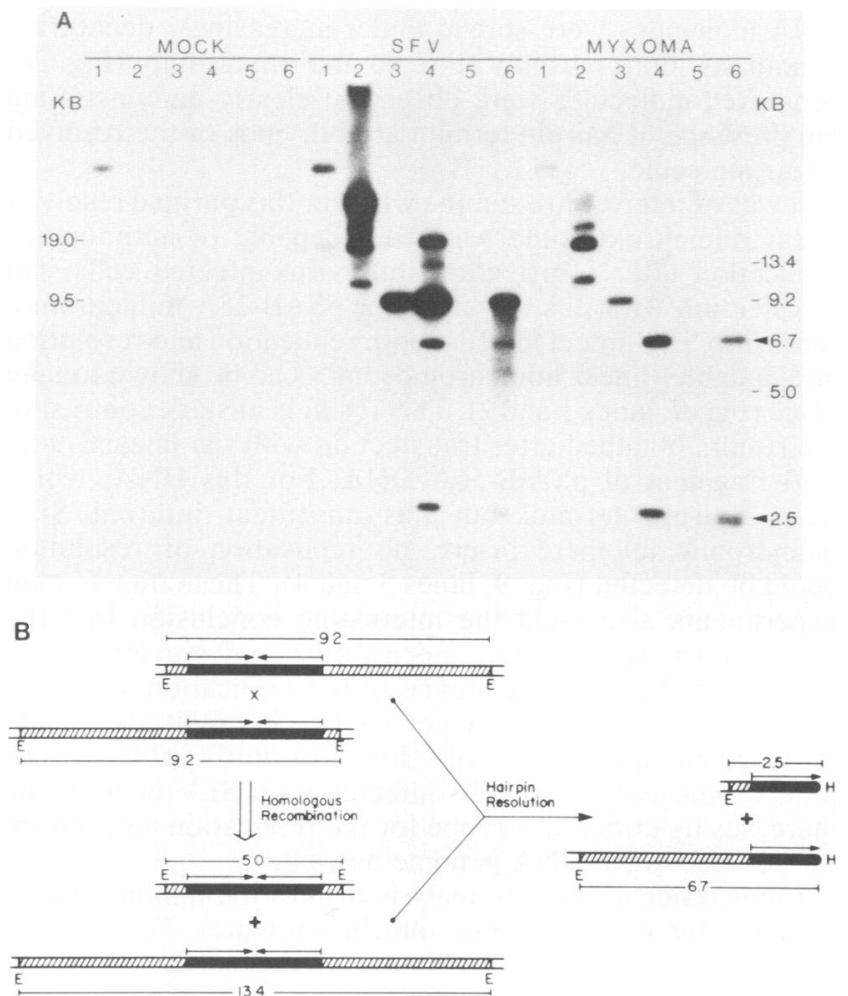

A distinctive pattern of $3.05-\mathrm{kb}$ monomers plus a laddered series of multimer-sized plasmid species was observed in the undigested DNA lane at $24 \mathrm{~h}$ after transfection (Fig. 6, lane U2). These lower-molecular-weight monomeric and multimeric species, at least up to the size of 8-mers, were also shown by restriction enzyme digestions and by electron microscopy (see below) to be linear DNA molecules. The presence of terminal hairpins in all of these species was indicated by snapback analysis (Fig. 6, lane U4). In addition, the termini of these linear molecules were mapped to the axis of symmetry of the insert (see HindIII and EcoRI digests in Fig. 6). When lineform or cruciform pVCB-5 DNA was transfected into vaccinia-infected cells, we obtained a similar pattern of cross-linked resolution products (not shown), except that much lower amounts of replicated, and therefore resolved, plasmid DNA were detected. That the generation of these resolved monomeric and multimeric minichromosomes was poxvirus dependent was demonstrated by transfecting mock-infected cells.

It was of particular interest to examine the abilities of vaccinia virus-infected cells to resolve the cloned SFV telomere and of SFV-infected cells to resolve the cloned vaccinia telomere. We therefore transfected $\mathrm{pVCB}-5$ into SFV-infected cells and pSAIB-56A into vaccinia-infected cells and analyzed the resulting plasmid DNA species as before (Fig. 7). The pattern of snapback monomer and multimer plasmid species obtained from SFV-infected cells

C

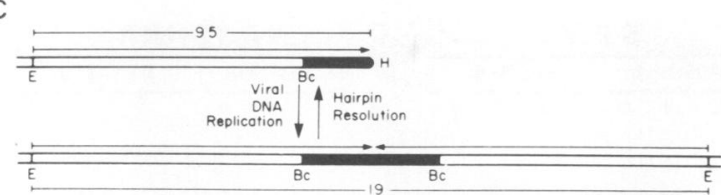

A

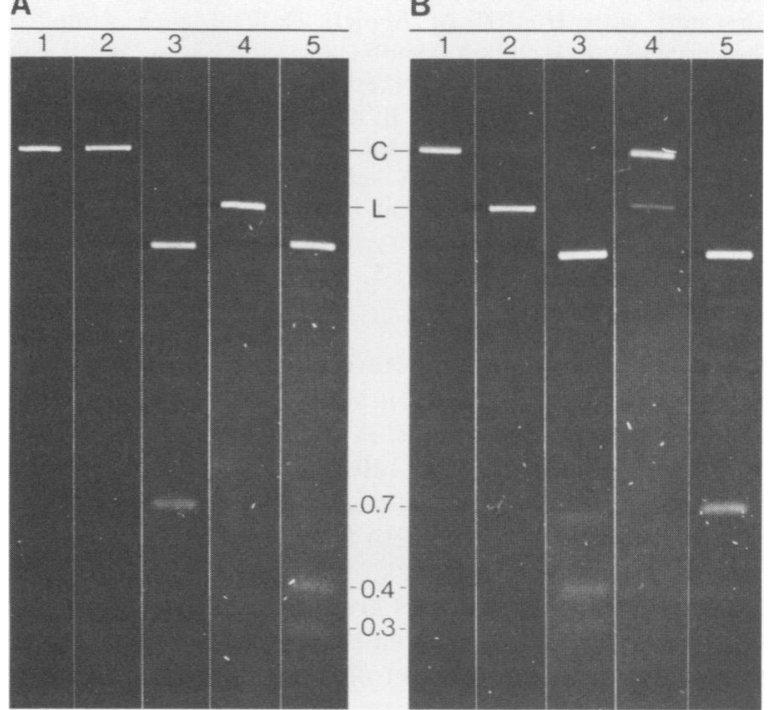

FIG. 4. Transfection of the yeast plasmid pYSF1-30 into poxvirus-infected cells. (A) Plasmid pYSF1-30, which contains the cloned SFV telomere in the inverted-repeat configuration (Fig. 1), was transfected into monolayers of rabbit SIRC cells that were mock infected or had been infected with SFV or myxoma virus at a multiplicity of infection of 1 . The DNA was extracted after $3 \mathrm{~h}$ (lanes 1,3 , and 5) and $24 \mathrm{~h}$ (lanes 2, 4, and 6) and was left undigested (lanes 1 and 2), digested with $E c o$ RI (lanes 3 and 4), or digested with $E c o$ RI followed by denaturation and quick chilling on ice (snapback treatment; lanes 5 and 6). DNA was electrophoresed in $0.7 \%$ agarose, blotted, and hybridized with the terminal 0.8-kb Clal restriction fragment of SFV. The washing conditions were sufficiently stringent to avoid cross-hybridization between the SFV probe and myxoma DNA (see the text). The resolved 6.7- and 2.5-kb EcoRI fragments of pYSF1-30 are indicated with arrows. (B) Map positions of recombination products of pYSF1-30 and of fragments containing the resolved hairpin. Each species is indicated on the right of panel A. (C) Relationship of the viral 9.5-kb EcoRI terminal restriction fragment to the transient $19-\mathrm{kb}$ dimeric replicative intermediate. The two species are indicated on the left of panel A. SFV telomere sequences are shown in black, yeast vector sequences are designated by diagonal hatchings, and SFV sequences which lie outside the terminal $B c / I$ sites are shown in white. E. EcoRI; Bc. Bc/l; H, hairpin termini.

tions of plasmids pSAlB-56A and pVCB-5 were transfected into SFV- or vaccinia-infected SIRC cells, and the extent of resolution into linear molecules containing viral hairpin telomeres was monitored after $24 \mathrm{~h}$. Figure 6 illustrates the extent of resolution in SFV-infected cells of the lineform pSAIB-56A (Fig. 5), but the results were identical when the input DNA was in the cruciform conformation (not shown).
FIG. 5. Lineform and cruciform conformations of pSAlB-56A. pSAIB-56A plasmid DNA was exposed to limited DNase I treatment to generate about 50\% nicked molecules. The nicked $(\mathrm{A})$ and covalently closed (B) plasmid species were purified as described in the text and were treated with either $\mathrm{T} 7$ resolvase (gene 3 endonuclease I) or $A f f I I$. The $\mathrm{T} 7$ resolvase cleaves specifically at the base of cruciforms, and $A f I I I$ will digest only the lineform configuration of the SFV palindrome because the single restriction site is located at the axis of symmetry (Fig. 3A). The $0.7-\mathrm{kb} P v u l l$ fragment of pSAlB-56A will appear as a 0.4- plus $0.3-\mathrm{kb}$ fragment when the palindromic insert has been resolved at the axis of symmetry. The faint linear bands in lanes A1 and 2 (nicked DNA) were not due to cleavage at the axis of symmetry; i.e.. upon $B g / l$ digestion, no 1.6-kb resolved species was observed (not shown). Lanes 1, Untreated DNA: lanes 2. T7 resolvase; lanes 3, T7 resolvase plus $P v u I I$; lanes 4, AflII; and lanes 5. AflI plus $P$ ivill. The numbers are in kilobases. C. Circular pSAIB-56A: L, full-length linear pSAIB$56 \mathrm{~A}(3.05 \mathrm{~kb})$. 


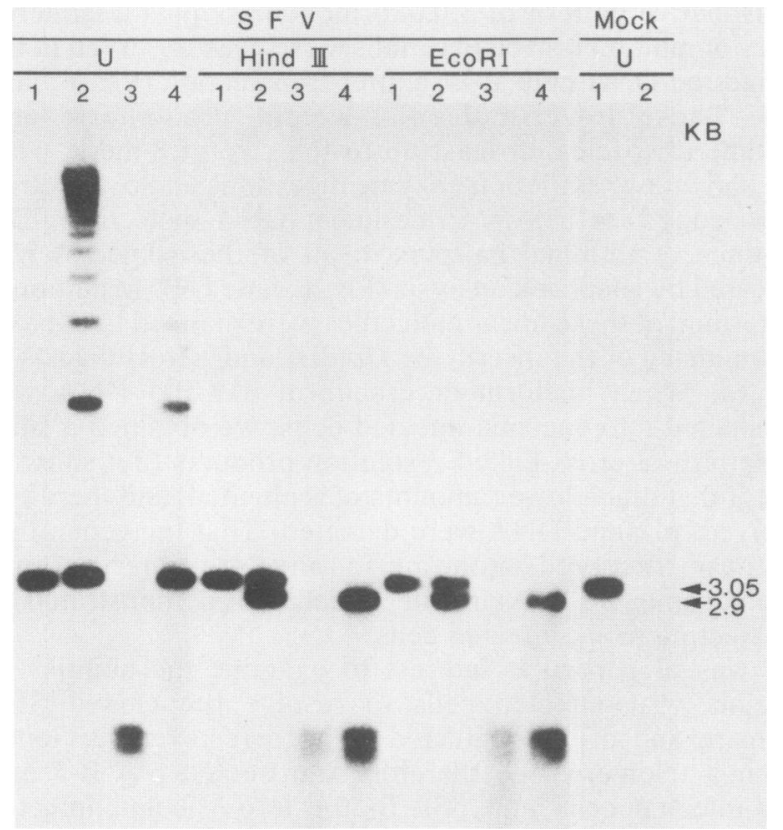

FIG. 6. Resolution of the cloned SFV telomere of pSAlB-56A in SFV-infected cells. pSAlB-56A DNA was converted quantitatively to the lineform configuration as described in the legend to Fig. 5 and was transfected into SFV- or mock-infected cells. DNA was harvested after 3 or $24 \mathrm{~h}$ as for Fig. 4 and was left either undigested (U) or digested with HindIII or EcoRI. Half of each sample was denatured and quick chilled (snapback) as for Fig. 4, and the DNA samples were analyzed by Southern blotting, with pUC DNA as probe. Lanes $1,3 \mathrm{~h}$; lanes $2,24 \mathrm{~h}$; lanes $3,3 \mathrm{~h}$ (snapback); lanes 4, $24 \mathrm{~h}$ (snapback). The 3.05-kb species corresponds to linearized pSAlB-56A with unresolved SFV sequences, and the $2.9-\mathrm{kb}$ species after EcoRI or HindIII digestion indicates fragments created by resolution at the axis of symmetry of the viral insert.

reflects resolution of the heterologous viral telomeres by SFV, although the resolution was somewhat less efficient than in the homologous case. A similar result was obtained with vaccinia-infected cells, although once again the total amount of resolved product was substantially less than in SFV-infected cells. Thus, both SFV and vaccinia are capable of resolving the telomeres of the heterologous virus.

Resolved minichromosomes are linear DNA molecules with intact viral hairpins at both ends. We have established that the observed resolution event cleaves the viral palindromes at or near the axis of symmetry of the insert in pSAlB-56A and pVCB-5 and that the complementary strands of the resolved molecules generated by this event are covalently linked. To establish unequivocally that the covalent linkage is located at the original axis of symmetry, we have purified by preparative gel electrophoresis the resolved monomer minichromosome derived from $\mathrm{pSAB}-28 \mathrm{~A}$, which contains a slightly larger SFV telomeric insert than does pSAlB-56A (see the legend to Fig. 1) but generates comparable quantities of minichromosome species. The palindromic nature of the insert in pSAB-28A is illustrated by the presence of cruciforms in covalently closed plasmid DNA (Fig. 8a), but as before, subsequent resolution events in transfected cells occur with equal efficiency with input lineform DNA. The resolved minichromosome was found to be a linear molecule with a length $(3.3 \mathrm{~kb})$ identical to that of the circular input pSAB-28A plasmid (Fig. 8b). When these purified linear
DNA molecules were spread under increasingly denaturing conditions, both partially (Fig. 8c and d) and fully (Fig. 8e) denatured molecules were observed, clearly demonstrating the presence of hairpin termini at both ends of the resolved linear molecule.

It was of interest to examine whether this purified resolved linear minichromosome was itself capable of autonomous replication after transfection into virus-infected cells. On transfection with this 3.3-kb linear pSAB-28A minichromosome into SFV-infected cells, both replication and resolution into daughter linear minichromosomes can be shown to take place (Fig. 9, lanes 1 and 2). This result is in stark contrast to the results obtained after transfection with the linear 1.9-kb Bgll fragment of pSAlB-56A DNA. For this DNA, which lacks hairpin termini but has an intact internal SFV palindromic telomere insert, no replication or resolution could be detected (Fig. 9, lanes 3 and 4). These transfection experiments also yield the interesting conclusion that the larger dimer, trimer, etc., species observed previously can be generated as a consequence of the replication and resolution of the monomer species itself. The ability to isolate microgram quantities of this low-molecular-weight minichromosome from cells infected with SFV or myxoma increases its utility as a probe for the replication mechanism of the intact viral-DNA genome as well.

Unidirectional deletion analysis defines the minimal target sequence for resolution into minichromosomes. To ascertain

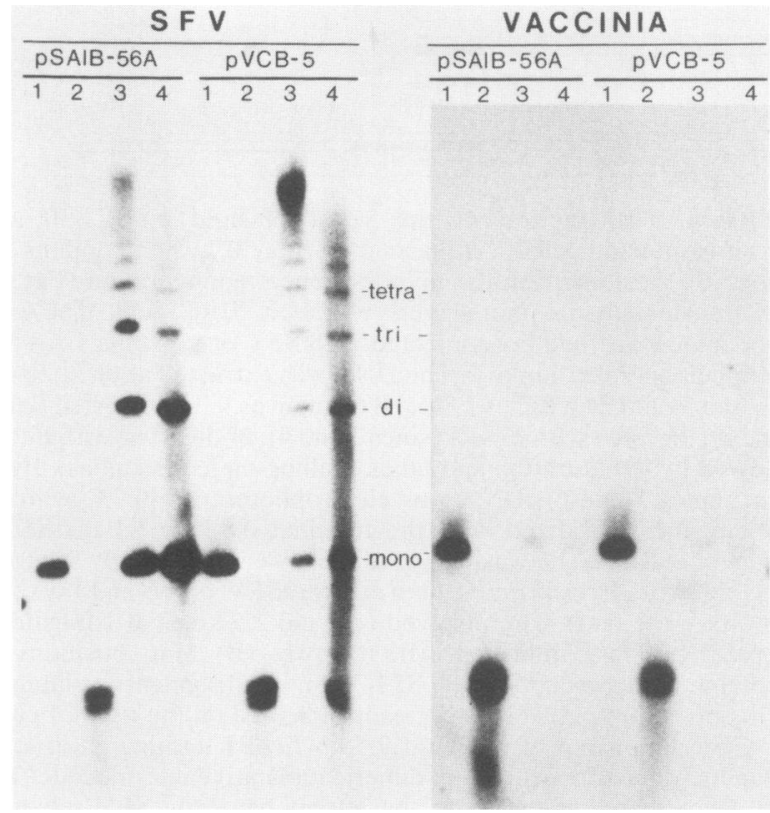

FIG. 7. Resolution of the SFV telomere in pSAIB-56A and the vaccinia telomere in pVCB-5 by the heterologous virus. Lineform plasmids pSAIB-56A and pVCB-5 were individually transfected into both SFV- and vaccinia-infected cells. The cellular DNA was harvested at $3 \mathrm{~h}$ (lanes 1 and 2) and $24 \mathrm{~h}$ (lanes 3 and 4) after transfection. A sample of each DNA was exposed to snapback treatment (lanes 2 and 4 ) before electrophoresis in agarose, as described in the legend to Fig. 4. The agarose gel was blotted and hybridized with pUC probe. The locations of plasmid monomers (mono) and oligomers (di, tri, and tetra) are indicated. The blot for SFV was exposed for $16 \mathrm{~h}$, whereas the blot for vaccinia was exposed for $96 \mathrm{~h}$. The oligomers of the vaccinia minichromosome are too faint to be seen here, but can be readily observed in Fig. 12. 

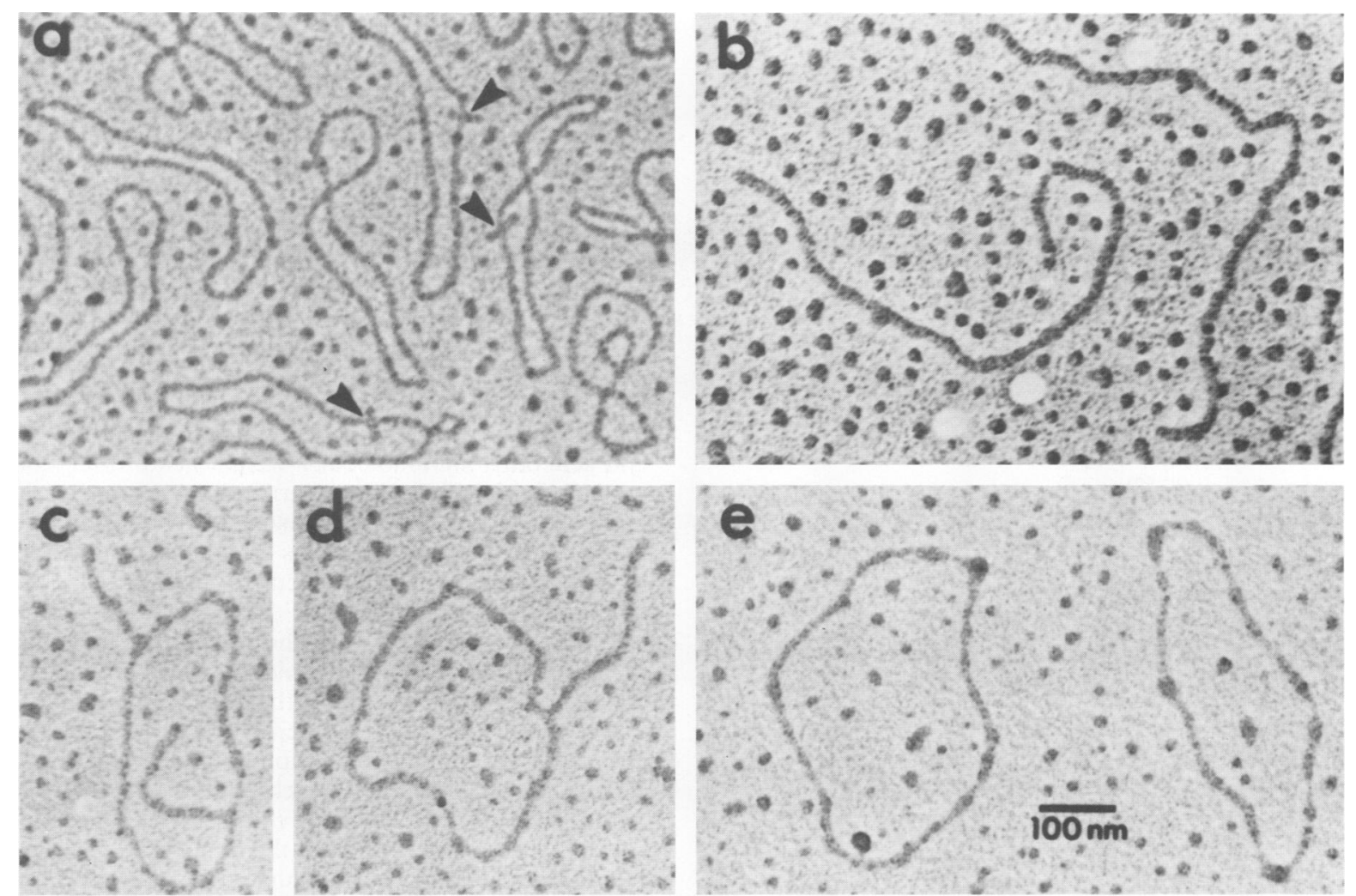

FIG. 8. Electron microscopy of the resolved monomer minichromosome of pSAB-28A. The circular plasmid pSAB-28A (see the legend to Fig. 1) was transfected into SFV-infected cells, and at $24 \mathrm{~h}$, the 3.3-kb minichromosome was purified as described in the text. (a) The presence of the palindromic viral insert in the input circular pSAB-28A is evidenced from the cruciform structures indicated by the arrows. (b) The gel-purified 3.3-kb resolved minichromosome of pSAB-28A. (c through e) Same DNA as in panel b, except prepared under partially (c and d) or fully (e) denaturing conditions.

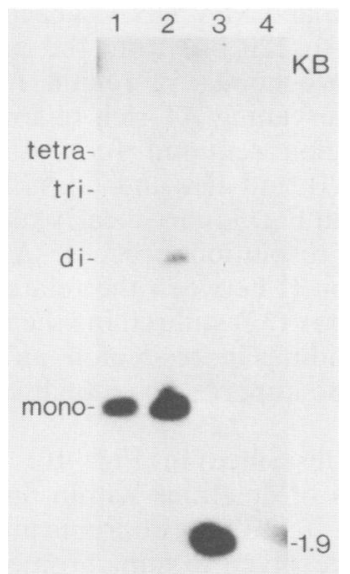

FIG. 9. Autonomous replication and resolution of the purified linear pSAB-28A minichromosome in SFV-infected cells. The 3.3-kb linear resolved $\mathrm{pSAB}-28 \mathrm{~A}$ minichromosome described in the legend to Fig. 8 was transfected into SFV-infected cells, and DNA was isolated after $3 \mathrm{~h}$ (lane 1) or $24 \mathrm{~h}$ (lane 2) and analyzed by Southern blotting, with pUC DNA as probe. As a control, the purified 1.9-kb linear $B g l$ fragment of pSAlB-56A, which includes the entire 322-bp unresolved viral telomeric insert (Fig. 3A), was similarly transfected, and DNA was analyzed after purification at 3 h (lane 3) or $24 \mathrm{~h}$ (lane 4). The locations of plasmid monomers (mono) and oligomers (di, tri, and tetra) are indicated. the minimal sequence domains required for the resolution of SFV and vaccinia telomeres, staggered unidirectional deletions were generated, with exonuclease III, in pSAlB-56A and pVCB-5. A total of 15 SFV clones and 7 vaccinia clones were chosen by virtue of their spectrum of insert sizes and were sequenced to confirm the precise boundaries of the deletions. Their relative map positions are indicated in Fig. 10. Each of these nested deletions was transfected into cells infected with the homologous virus, and the extent of resolution of each deletion into linear minichromosomes was monitored. The degree of resolution of each of these deletions in either SFV- or vaccinia-infected cells can be seen in the undigested DNA samples shown in Fig. 11 (SFV) and 12 (vaccinia). We have included an ethidium bromide-stained gel in Fig. 11 to emphasize the large amount of linearminichromosome products generated in SFV-infected cells. Analogous bands from vaccinia-infected cells cannot be visualized and have been detected only by blotting. The results of these blots have been summarized in Fig. 10. We have also observed that the patterns of monomers, multimers, and high-molecular-weight concatemers is unaffected by the amount of input DNA; i.e., 4, 20, or $100 \mathrm{ng}$ of input plasmid DNA of a variety of vaccinia and SFV deletion clones resulted in a virtually identical pattern of minichromosome bands for each plasmid (not shown).

\section{DISCUSSION}

The covalently closed hairpin telomeres of two different poxviruses, SFV and vaccinia virus, have been cloned in 


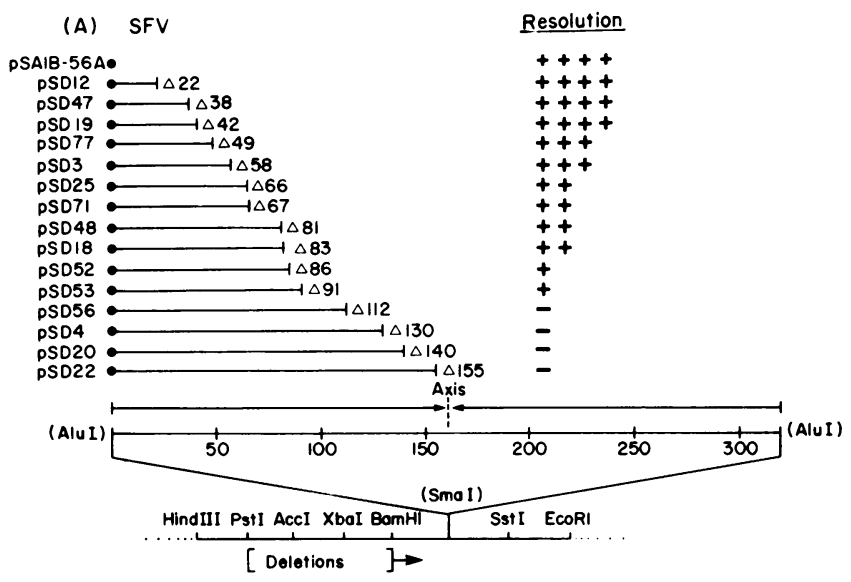

(B) Voccinio

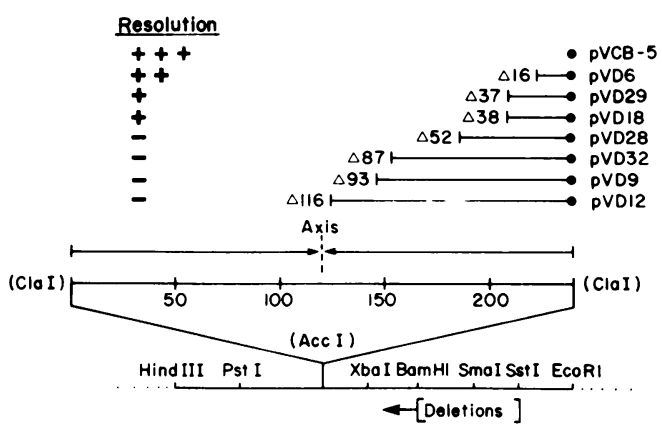

FIG. 10. Analysis of unidirectional deletions of the SFV and vaccinia telomeres. Unidirectional deletions of pSAlB-56A (A) and pVCB-5 (B) were created by exonuclease III as described in the text. Individual deletion clones were sequenced, and the number of deleted nucleotides in each deletion is indicated by the $\Delta$ number. The deletions of pSAIB-56A are referred to as the pSD series, and those of pVCB-5 are the pVD series. The extent of resolution of each clone is designated from - (no resolution) to ++++ (maximal resolution) and represents a summary of the data shown in Fig. 11 and 12 .

yeast cells and in recombination-deficient $E$. coli in the inverted-repeat configuration. The viral telomeres in these cloned DNAs have been, in effect, "frozen" in a replicative intermediate conformation identical to that observed transiently during poxviral-DNA replication $(13 a, 30,31)$. We have shown that plasmid clones possessing these viral inverted-repeat inserts, when transfected into poxvirusinfected cells, serve as substrates for trans-acting virusinduced proteins which efficiently convert the circular plasmids into linear minichromosomes with bona fide viral hairpin telomeres.

The DNA sequences of these two poxviral telomeres suggest a common ancestral origin (summary in Fig. 13). (i) The region immediately flanking the axis of symmetry of the inverted repeat is very AT rich for both viruses and contains nonpalindromic bases ( 14 for vaccinia and 8 for SFV) close to the axis. (ii) Adjacent to this AT-rich region of both the SFV and vaccinia telomers are three highly conserved regions. Region I, closest to the axis of symmetry, is an 11-bp sequence, $(\mathrm{T})_{7} \mathrm{CTAG}$, which is perfectly conserved between the two genomes. The adjacent region II is only partly conserved in terms of sequence, but is a stretch in which the order of purines and pyrimidines is identical in 12 of 13 bp. Region III is a 17-bp (for vaccinia) or 18-bp (for SFV) region which also has, except for a single base pair, a conserved order of purines and pyrimidines. Vaccinia, unlike SFV, also contains a partial tandem repeat of this region III that follows a similar theme of purines and pyrimidines (region IIIa).

The significance of regions I to III for the resolution of the viral replicative intermediate inverted repeats into daughter hairpin termini was deduced from the varying degrees of in vivo resolution of different deletion derivatives by the homologous virus. It has previously been found that when exogenous circular plasmid DNA is transfected into poxvirus-infected cells, the input DNA replicates autonomously in a sequence-independent fashion in the cytoplasm and generates high-molecular-weight head-to-tail concatemers consisting of long linear arrays of the transfecting plasmid sequences (13a). The present study clearly shows that when input circular plasmids containing the palindromic target sequences are allowed to replicate in poxvirusinfected cells, the resulting high-molecular-weight concatemers are substrates for the presumptive viral proteins responsible for telomere resolution. The telomere of vaccinia (plasmid pVCB-5) and that of SFV (plasmid pSAlB56A) were efficiently resolved by the homologous virus, generating predominantly monomer, or lower-multimersized, minichromosomes which contained intact viral hairpins at both termini. The failure to resolve all potential target sites presumably accounts for the dimer and longer-oligomer DNA species. A similar incomplete resolution of replicated viral genomes in infected cells is apparently responsible for the continuing presence of the dimer replicative intermediates of the terminal restriction fragments observed even at late times during poxvirus DNA replication $(13 \mathrm{a}, 30)$.

The mapping of telomeric DNA sequences required for efficient in vivo resolution made use of unidirectional deletion derivatives of plasmids pVCB-5 and pSAlB-56A and clearly implicates the conserved regions I, II, and III. These regions of vaccinia and SFV DNAs are located at comparable distances (50 to $120 \mathrm{bp}$ ) from the palindromic axis of symmetry. The two copies of region I, and adjacent sequences in the intervening AT-rich region (Fig. 13), constitute the core region required for basal resolution. The adjacent regions, II and III, and possibly the small palindromes indicated in Fig. 13, are clearly required for maximal efficiency of the resolution process. A single nucleotide difference in region II between the related orthopoxviruses vaccinia and cowpox (32) still retains the conserved order of purines and pyrimidines in this region, an observation that is compatible with the importance of such sequence conservation.

The plasmids described in Fig. 10, which contain an overlapping series of deletions within one axis of the viral palindrome, were found to be replicated to comparable extents but were resolved to minichromosome species with various efficiencies (Fig. 11 and 12). The following observations indicate that the loss of resolution capability by deletions which extend closer than 80 to $100 \mathrm{bp}$ from the symmetry axis is not due simply to the size reduction of any nonspecific palindromic sequence down to a minimal size: (i) when the nondeleted vaccinia and SFV clones were tested under identical conditions in cells infected by the heterologous virus, resolution could be readily detected but was always substantially less efficient than in the homologous pairing; and (ii) synthetic palindromes, consisting of circular head-to-head dimers of bacterial plasmid DNA, replicate 


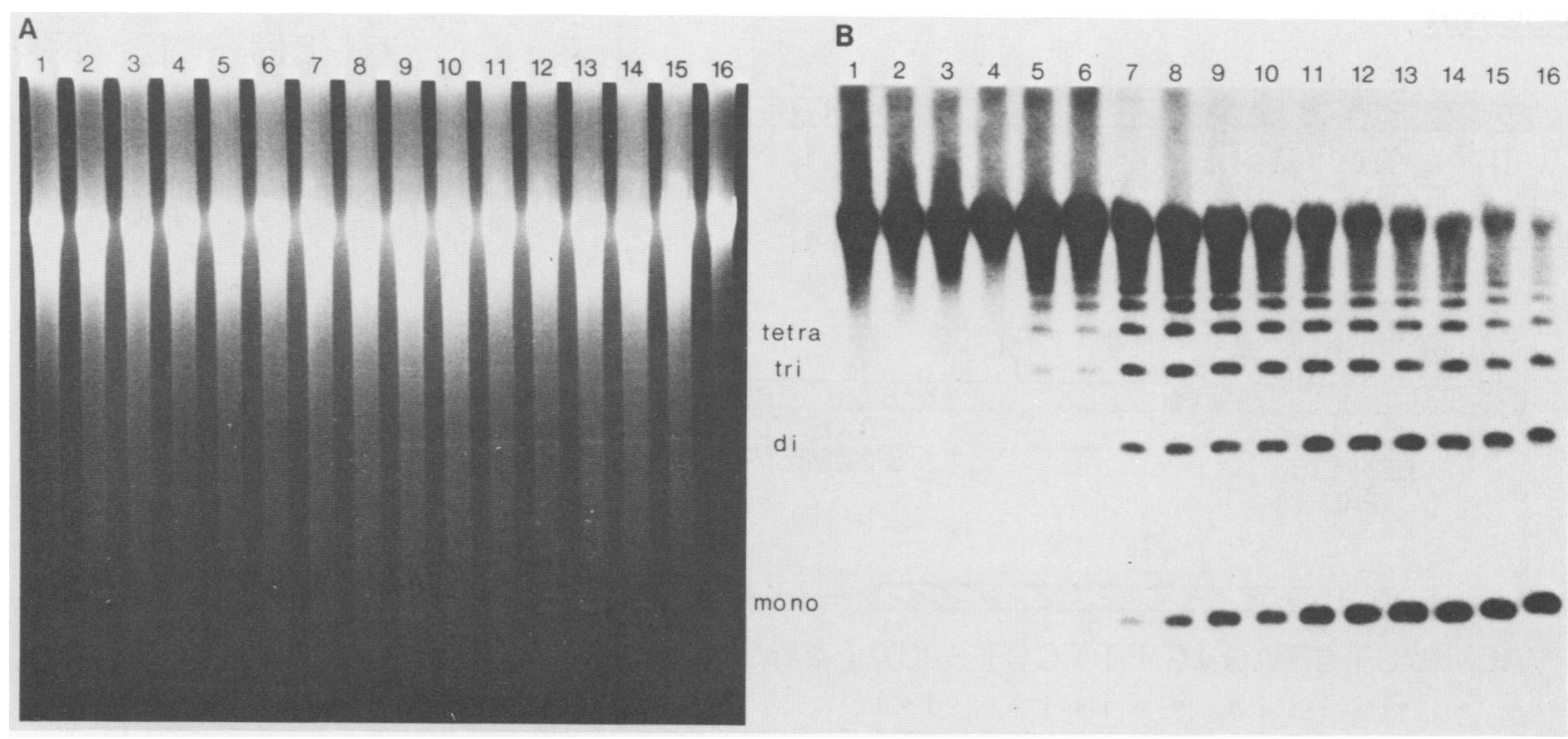

FIG. 11. Comparative resolution rates of the SFV telomere unidirectional deletions. Plasmid pSAIB-56A and the 15 deletion derivatives described in Fig. 10A were transfected into SFV-infected cells, and the DNA was extracted after $24 \mathrm{~h}$, electrophoresed in $0.7 \%$ agarose gel, and stained with ethidium bromide (A). The gel was then blotted and hybridized with pUC DNA (B). Lanes 1 through 16 represent plasmids pSD22, $-20,-4,-56,-53,-52,-18,-48,-71,-25,-3,-77,-19,-47$, and -12 and pSAlB-56A, respectively. Mono, plasmid monomers; di, tri, and tetra, oligomers.

with good efficiency but do not resolve to any significant degree to low-molecular-weight species (not shown).

The size distribution of the resolved minichromosomes for many of the deletion clones, including those which displayed the highest amounts of resolution, extended from unit-length monomers right up to species of high molecular weight. The observation that the amount of input plasmid DNA for any one particular clone does not affect this spectrum of resolved

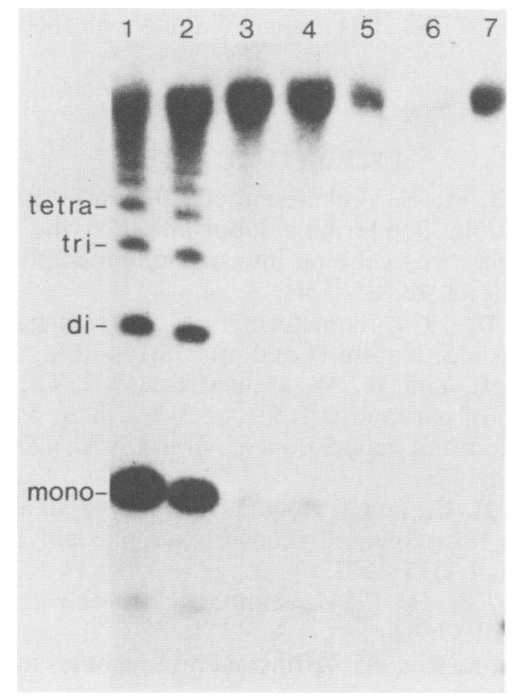

FIG. 12. Comparative resolution rates of the vaccinia telomere unidirectional deletions. Plasmid pVCB-5 and the six deletion derivatives described in Fig. 10B were transfected into vacciniainfected cells, and DNA was harvested after $24 \mathrm{~h}$, electrophoresed, blotted, and hybridized with pUC DNA. Lanes 1 through 7 represent plasmids pVCB-5 and pVD6, -29, $-18,-28,-32$, and -9 , respectively. The faint, fast-migrating band in each lane represents residual supercoiled input plasmids. Mono, plasmid monomers; di, tri, and tetra, oligomers. product sizes implies that the larger concatemeric linear minichromosomes are end products and that the internal viral telomeric sequences are no longer available for resolution. We suggest that the accessibility, or possibly the specific conformational state, of the target telomeric sequences may be critical for telomere resolution. As an example, superhelical tension within the replicating plasmid DNA could provide the necessary energy for a localized conformational transition (such as cruciform extrusion) required for the resolution event in vivo. In this regard it is noteworthy to mention that transient intracellular cruciforms have been proposed as possible intermediates during telomere resolution $(22,26,28)$. The availability of the in vivo assay for telomere resolution described here may allow the experimental testing of various models which have been proposed for telomere resolution (reviewed in reference 8).

Vaccinia virus and SFV are members of different genera of the poxvirus family, and attempts to find any DNA sequence homology between their genomes by hybridization analysis (15, 40; unpublished data) have been unsuccessful. In addition, the complete DNA sequence within the $12.4-\mathrm{kb}$ terminal inverted repeat of SFV has been determined and is unrelated to any published vaccinia sequences (38; C. Upton and G. McFadden, Virology, in press). The limited conservation of sequences near the hairpin telomeres of these two viruses is the first evidence that their telomeres may have been derived from a common ancestral sequence. The similarity of sequences responsible for telomere resolution of both vaccinia and SFV appears to be a reflection of the conservation of the resolution mechanism itself. The structural and functional conservation of the telomeres in these two divergent viruses is reminiscent of the conservation of sequence features and function of telomeres among lower eucaryotes (for reviews, see references 5, 6, and 8). Even though it is not clear whether the chromosomal telomeres from lower eucaryotes contain hairpin structures, it has been observed that an artificially constructed palindrome containing the rDNA telomere of Tetrahymena species could be 


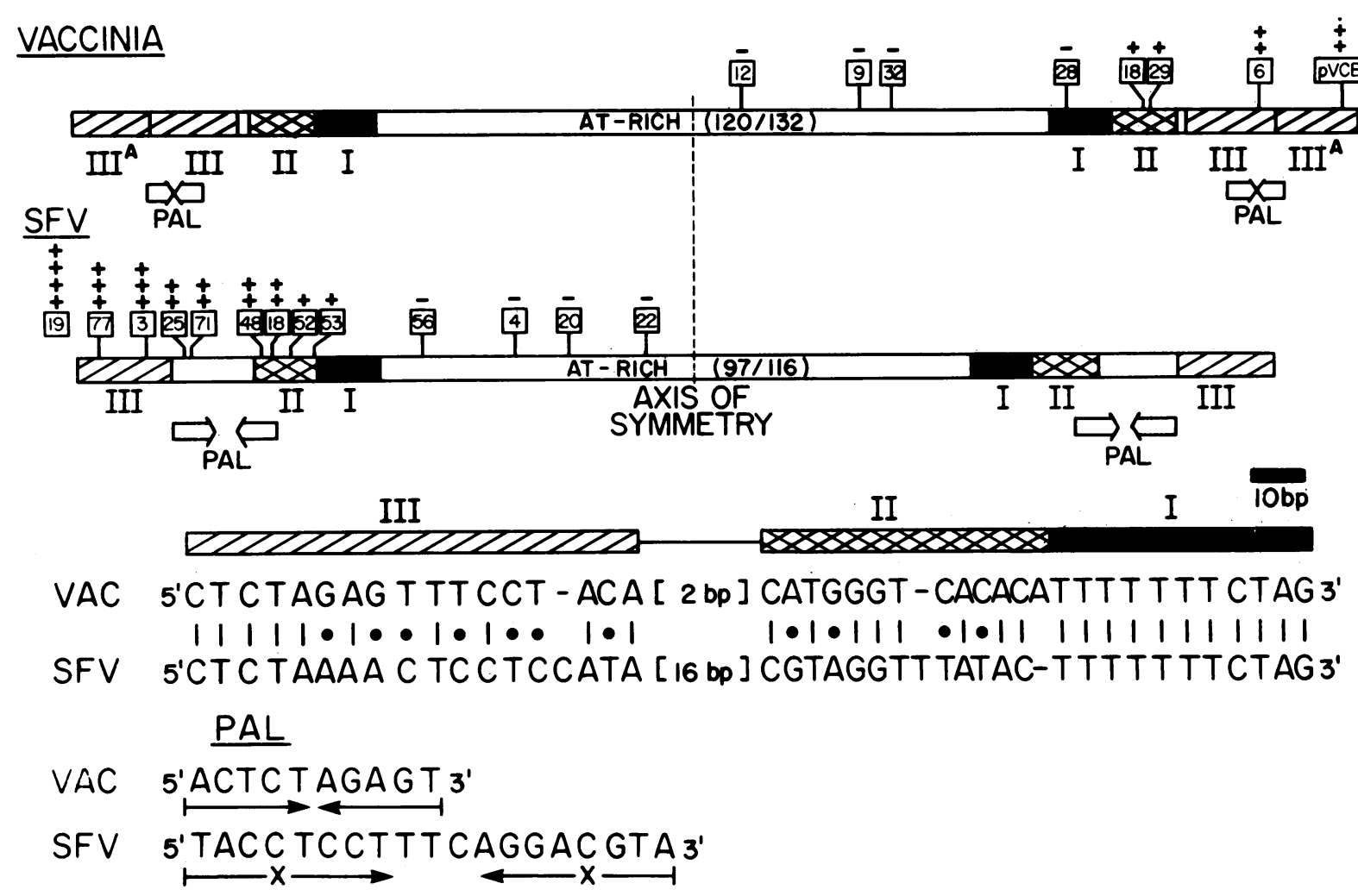

FIG. 13. Conserved DNA sequences of SFV and vaccinia required for maximal telomere resolution. The DNA sequence features of the inverted-repeat configurations of the telomeres of vaccinia and SFV are highlighted. The axes of symmetry of the two telomeric segments are aligned. The central $104 \mathrm{bp}$ of vaccinia and $64 \mathrm{bp}$ of SFV are imperfect palindromes (Fig. 3). The fractions in brackets within the AT-rich central regions represent the actual numbers of AT pairs. The regions of sequence conservation flanking the AT-rich central region of SFV and vaccinia are designated I, II, and III. Region I (black) is an 11-bp sequence perfectly conserved between SFV and vaccinia. Immediately adjacent to region I is the 13-bp region II (cross-hatch) with 8 of 13 bases perfectly conserved (indicated by slashes) and another 4 bases in which the order of purines and pyrimidines is conserved (indicated by dots). In region III (diagonals), with 17 (vaccinia) or 18 (SFV) bp, the order of purines and pyrimidines is exactly conserved, with only a single deleted base in vaccinia. Region IIIa of vaccinia is related to III but is truncated and does not appear in SFV. A 19-bp sequence with dyad symmetry in SFV and a 10-bp perfect palindrome (PAL) in vaccinia are also indicated. The extent of resolution of the SFV and vaccinia deletions described in Fig. 10 is indicated along with the clone numbers above the schematic sequence.

resolved efficiently in yeast cells (36). In addition to poxviruses and parvoviruses, hairpin termini have been identified in Paramecium mitochondrial DNA (33) and extrachromosomal copies of rDNA in Tetrahymena species (7).

The characterization of the mechanisms of the replication and resolution of poxviral hairpin termini may become instrumental in unveiling related mechanisms in the cellular genome. In this regard, the DNA segments identified here containing regions I to III may provide suitable probes for sequence-specific proteins involved in the resolution of viral telomeres and may provide insights into the nature of telomere resolution of other higher-order chromosomes as well.

\section{ACKNOWLEDGMENTS}

We are grateful for the technical assistance of R. Maranchuk, A. Wills, and R. Bradley and for the help of A. Opgenorth with the DNA sequencing. We thank A. R. Morgan and P. Dickie for helpful discussions. The manuscript was prepared with the expert assistance of B. Bellamy.

A.D. and C.U. are supported by postdoctoral fellowship awards from the Alberta Heritage Foundation for Medical Research (AHFMR). G.M. is an AHFMR scholar. This work was funded by the Medical Research Council of Canada.

\section{LITERATURE CITED}

1. Baroudy, B. M., S. Venkatesan, and B. Moss. 1982. Incomplete base-paired flip-flop terminal loops link the two DNA strands of the vaccinia virus genome into one uninterrupted polynucleotide chain. Cell 28:315-324.

2. Beggs, J. D. 1978. Transformation of yeast by a replicating hybrid plasmid. Nature (London) 275:104-108.

3. Berns, K. I., and W. W. Hauswirth. 1982. Organization and replication of parvovirus DNA, p. 3-36. In A. S. Kaplan (ed.), Organization and replication of viral DNA. CRC Press, Inc., Boca Raton, Fla.

4. Birnboim, H. C., and J. Doly. 1979. A rapid alkaline extraction procedure for screening recombinant plasmid DNA. Nucleic Acids Res. 7:1513-1523.

5. Blackburn, E. H. 1984. Telomeres: do the ends justify the means? Cell 37:7-8.

6. Blackburn, E. H. 1985 . Artificial chromosomes in yeast. Trends Genet. 1:8-12.

7. Blackburn, E. H., and J. G. Gall. 1978. A tandemly repeated sequence at the termini of the extrachromosomal ribosomal RNA genes in Tetrahymena. J. Mol. Biol. 120:33-53.

8. Blackburn, E. H., and J. W. Szostak. 1984. The molecular structure of centromeres and telomeres. Annu. Rev. Biochem. 53:163-194.

9. Block, W., C. Upton, and G. McFadden. 1985. Tumorigenic poxviruses: genomic organization of malignant rabbit virus, a recombinant between Shope fibroma virus and myxoma virus. 
Virology 140:113-124.

10. Boissy, R., and C. R. Astell. 1985. An E. coli recBC sbcB recF host permits the deletion-resistant propagation of plasmid clones containing the 5'-terminal palindrome of minute virus of mice. Gene 35:179-185.

11. Dales, S., V. Milovanovitch, B. G. T. Pogo, S. B. Weintraub, T. Huima, S. Wilton, and G. McFadden. 1978. Biogenesis of vaccinia: isolation of conditional lethal mutants and electron microscopic characterization of their phenotypically expressed defects. Virology 84:403-428.

12. Dales, S., and B. G. T. Pogo. 1982. The biology of poxviruses. Springer-Verlag, New York.

13. Davis, R. W., M. Simon, and N. Davidson. 1971. Electron microscope heteroduplex methods for mapping regions of base sequence homology in nucleic acids. Methods Enzymol. 21:413-428.

13a.DeLange, A. M., and G. McFadden. 1986. Sequence-nonspecific replication of transfected plasmid DNA in poxvirus-infected cells. Proc. Natl. Acad. Sci. USA 83:614-618.

14. DeLange, A. M., B. Futcher, R. Morgan, and G. McFadden. 1984. Cloning of the vaccinia virus telomere in a yeast plasmid vector. Gene 27:13-21.

15. DeLange, A. M., C. Macaulay, W. Block, T. Mueller, and G. McFadden. 1984. Tumorigenic poxviruses: construction of the composite physical map of the Shope fibroma virus genome. J. Virol. 50:408-416.

16. deMassy, B., F. W. Studier, L. Dorgai, E. Appelbaum, and R. A. Weisberg. 1984. Enzymes and sites of genetic recombination: studies with gene-3 endonuclease of phage T7 and with siteaffinity mutants of phage $\lambda$. Cold Spring Harbor Symp. Quant. Biol. 49:715-726.

17. Devenish, R. J., and C. S. Newlon. 1982. Isolation and characterization of yeast ring chromosome III by a method applicable to other circular DNAs. Gene 18:277-288.

18. DiCapua, E., A. Engel, A. Stasiuk, and T. Koller. 1982. Characterization of complexes between recA protein and duplex DNA by electron microscopy. J. Mol. Biol. 157:87-103.

19. Henikoff, S. 1984. Unidirectional digestion with exonuclease III creates targetted breakpoints for DNA sequencing. Gene 28:351-359.

20. Hsu, P. L., and A. Landy. 1984. Resolution of synthetic att-site Holliday structures by the integrase protein of bacteriophage $\lambda$. Nature (London) 311:721-726.

21. Langridge, J., P. Langridge, and P. L. Bergquist. 1980. Extraction of nucleic acids from agarose gels. Anal. Biochem. 103:264-271.

22. Lilley, D. M., and B. Kemper. 1984. Cruciform-resolvase interactions in supercoiled DNA. Cell 36:413-422.

23. Maxam, A. M., and W. Gilbert. 1980. Sequencing end-labeled DNA with base-specific chemical cleavages. Methods Enzymol. 65:499-560.

24. McFadden, G., and S. Dales. 1979. Biogenesis of poxviruses: mirror-image deletions in vaccinia virus DNA. Cell 18:101-108.
25. McFadden, G., and S. Dales. 1982. Organization and replication of poxvirus DNA, p. 173-190. In A. S. Kaplan (ed.), Organization and replication of viral DNA. CRC Press, Inc., Boca Raton, Fla.

26. McFadden, G., and A. R. Morgan. 1982. DNA cruciform structures: implications for telomere replication in eukaryotes and instability of long palindromic DNA sequences in prokaryotes. J. Theor. Biol. 97:343-349.

27. Messing, J. 1983. New M13 vectors for cloning. Methods Enzymol. 101:20-77.

28. Mizuuchi, K., B. Kemper, J. Hays, and R. A. Weisberg. 1982. T4 endonuclease VII cleaves Holliday structures. Cell 29:357-365.

29. Moss, B. 1985. Replication of poxviruses, p. 685-704. In B. N. Fields (ed.), Virology. Raven Press, Publishers, New York.

30. Moss, B., E. Winters, and E. V. Jones. 1983. Replication of vaccinia virus, p. 449-461. In N. R. Cozarelli (ed.), Mechanism of DNA replication and recombination. Alan R. Liss, Inc., New York.

31. Moyer, R. N., and R. L. Graves. 1981. The mechanism of cytoplasmic orthopoxvirus DNA replication. Cell 27:391-401.

32. Pickup, D. J., D. Bastia, H. O. Stone, and W. K. Joklik. 1982. Sequence of terminal regions of cowpox virus DNA: arrangement of repeated and unique sequence elements. Proc. Natl. Acad. Sci. USA 79:7112-7116.

33. Pritchard, A. E., and D. J. Cummings. 1981. Replication of linear mitochondrial DNA from Paramecium: sequence and structure of the initiation-end crosslink. Proc. Natl. Acad. Sci. USA 78:7341-7345.

34. Rigby, P. W. J., M. Dieckmann, C. Rhodes, and P. Berg. 1977. Labeling DNA to high specific activity in vitro by nick translation with DNA polymerase I. J. Mol. Biol. 113:237-251.

35. Sanger, F., A. R. Coulson, B. G. Barell, A. J. H. Smith, and B. A. Roe. 1980 . Cloning in single-stranded bacteriophage as an aid to rapid DNA sequencing. J. Mol. Biol. 143:161-178.

36. Szostak, J. W. 1983. Replication and resolution of telomeres in yeast. Cold Spring Harbor Symp. Quant. Biol. 47:1187-1194.

37. Szostak, J. W., and E. H. Blackburn. 1982. Cloning yeast telomeres on linear plasmid vectors. Cell 29:245-255.

38. Upton, C., and G. McFadden. 1986. DNA sequence homology between the terminal inverted repeats of Shope fibroma virus and an endogenous cellular plasmid species. Mol. Cell. Biol. 6:265-276.

39. West, S. C., and A. Körner. 1985. Cleavage of cruciform DNA structures by an activity from Saccharomyces cerevisiae. Proc. Natl. Acad. Sci. USA 82:6445-6449.

40. Wills, A., A. M. DeLange, C. Gregson, C. Macaulay, and G. McFadden. 1983. Physical characterization and molecular cloning of the Shope fibroma virus genome. Virology 130:403-414.

41. Winters, E., B. M. Baroudy, and B. Moss. 1985. Molecular cloning of the terminal hairpin of vaccinia virus DNA as an imperfect palindrome in an $E$. coli plasmid. Gene 37:221-228.

42. Wittek, R. 1982. Organization and expression of the poxvirus genome. Experientia 38:285-310. 